\title{
Adam Smith: el capitalismo y su frustrado proyecto de civilización ${ }^{1}$
}

\section{Ariadna Cazenave*}

Universidad de Buenos Aires

ariadnacazenave@gmail.com

\section{Pablo Enrique Levín}

Universidad de Buenos Aires
Revista Cultura Económica

Año XXXIX $\bullet \mathrm{N}^{\circ} 101$

Junio 2021: 50-66

https://doi.org/10.46553/cecon.39.101.2021.p50-66

Resumen: En el presente trabajo nos proponemos reconstruir el problema que interpretamos guía la obra de Adam Smith: la pregunta por la viabilidad histórica de la sociedad moderna. Para tal fin, procuramos argumentar: 1) que tanto La teoría de los sentimientos morales como La riqueza de las naciones ponen de relieve que el pleno despliegue del comercio es a la vez necesario y problemático, hasta gravemente peligroso, como fundamento de la nueva sociedad; 2) que ambas obras apuntan a argumentar, desde ángulos complementarios, en qué sentido y bajo qué condiciones la sociedad moderna es viable. Si de suyo es de interés comprobar que Smith había reflexionado sobre tal problema, aún más relevante es la solución misma en la que trabajó a lo largo de toda su carrera, sin alcanzarla: el desarrollo de un fundamento científico y filosófico para una teoría de la jurisprudencia moderna que posibilite la gestación y maduración de una sociedad bien gobernada.

Palabras clave: Adam Smith; Economía política; Historia del pensamiento económico; Valor; Filosofía de la ilustración

\section{Adam Smith: capitalism and its frustrated project of civilization}

Abstract: In this paper we aim to address the problem that we interpret as guiding Adam Smith's work: the question of the historical viability of modern society. To this end, we seek to argue: 1) that both The Theory of Moral Sentiments and The Wealth of Nations show that the full deployment of trade is both necessary and problematic, even seriously dangerous, as the foundation of the new society; 2) that both works discuss, from complementary angles, in what sense and under what conditions modern society is viable. If it is of interest to note that Smith reflected on such a problem, even more relevant is the very solution on which he worked throughout his career, without reaching it: the development of a scientific and philosophical foundation for a theory of modern jurisprudence that would make possible the conception and progress of a wellgoverned society.

* Recibido: 08/04/2021 - Aprobado: 01/06/2021 
Keywords: Adam Smith; Political economy; History of economic thought; Value; Philosophy of enlightenment

\section{Introducción}

En vísperas de una transformación irreversible de la historia, el Siglo de las Luces tuvo la pretensión de reunir la totalidad de la experiencia social de su época en una síntesis filosófica: esta sería el fundamento de un proyecto político y jurídico civilizatorio. La época de la Ilustración asumió la misión de forjar un compendio de todo el conocimiento relevante de su tiempo, ya no basándose en la revelación sino en la filosofía y la ciencia, que no solo le permitiera tener una imagen coherente y abarcadora del mundo, sino que oficiara de guía para la concreción de una sociedad donde reinaran las promesas modernas (Levín et al., 2018: 24). Para sus protagonistas, se trataba de la liberación humana a través de la ciencia y la filosofía, de la emancipación de las cadenas del dogmatismo, de la superstición, de la "tutela". El hombre alcanzaría por fin la mayoría de edad a condición de que tuviera el valor de servirse de su propia razón (Kant, 1985: 25). Retrospectivamente advertimos que se trató de un proyecto inconcluso, no cabalmente realizado, y con más urgencia que entonces debemos comprender en qué radicó su incompletitud.

En el presente trabajo nos embarcamos en la reconstrucción de un problema que recorre la obra de uno de los grandes exponentes de aquel proyecto, Adam Smith: su fina y meticulosa investigación sobre la viabilidad histórica de la sociedad moderna. Smith, como se sabe, no emplea la palabra "capitalismo", pero basta reformular la pregunta para que quede patente la actualidad del problema: ¿es compatible la civilización democrática con el capitalismo?

Tanto La teoría de los sentimientos morales (TSM) como la Investigación sobre la naturaleza y causa de la riqueza de las naciones $(R N)$ ponen de relieve que el pleno despliegue del comercio (para nosotros, capitalista) es a la vez necesario y problemático, hasta gravemente peligroso, como fundamento de la nueva sociedad. $\mathrm{Y}$ ambas obras apuntan a argumentar, desde ángulos complementarios, en qué sentido y bajo qué condiciones la sociedad moderna es viable. Si suyo es de interés comprobar que Smith había reflexionado sobre tal problema, aún más relevante es la solución misma en la que trabajó a lo largo de toda su carrera, sin 
alcanzarla: el desarrollo de un fundamento científico y filosófico para una teoría de la jurisprudencia moderna que posibilite la gestación y maduración de una sociedad bien gobernada.

Procuraremos mostrar que la reconstrucción de esta pregunta y la identificación de los límites con los que choca Smith en su intento por responderla nos ofrece ocasión para reflexionar acerca de los lazos entre la economía política y otros campos de la ciencia y la filosofía, e imaginar la posibilidad de un nuevo proyecto de síntesis en el campo de las ciencias sociales. Nos interesa particularmente una pista que sigue el autor: el papel que juega en su proyecto filosófico la economía política y, especialmente, uno de sus conceptos fundamentales, el de valor.

Para Smith, sus desarrollos en los campos de la moral y de la economía política no son autónomos, sino que forman parte de un ambicioso proyecto filosófico que tiene la pretensión de que el conjunto de la ciencia y la filosofía constituya un cuerpo coherente para que el pensamiento teórico sea cabalmente práctico. En su obra se pueden apreciar las reflexiones de un autor que proyecta las posibilidades de gestación y nacimiento de una civilización universal. Su obra es la de una época de transición histórica, en la que generaciones de filósofos procuraron hallar en la filosofía claves para la proyección de la máxima aspiración de la sociedad humana y de cómo alcanzarla.

Intentaremos una destilación conceptual conjunta de ambas obras, la $T S M$ y la $R N$, con el objetivo de reconstruir dos importantes problemas teóricos que Smith formula respectivamente en cada una de las obras. El trabajo está dividido en tres partes. En primer lugar, presentamos el problema que, interpretamos, guía las dos obras de Smith: la pregunta por los principios de la naturaleza humana capaces de asegurar la armonía y factibilidad de la sociedad moderna. En segundo lugar, reconstruimos el principio general sobre el que el autor apoya una primera respuesta a esa pregunta: la simpatía. En tercer lugar, dirigimos la mirada hacia la $R N$ para reconstruir lo que interpretamos como una segunda respuesta a la pregunta que no había logrado responder en la TSM, apoyada en el principio general de valor como mecanismo de articulación de la sociedad mercantil. Por último, enunciamos algunas conclusiones prospectivas de nuestra investigación. 


\section{El proyecto filosófico de Adam Smith. Introducción a sus principales preguntas de investigación}

Abarcando las dos obras de Smith en una sola mirada, advertimos un motivo común a ellas: la moderna sociedad civil, tal como a la sazón, en vísperas de la transformación del capitalismo comercial en capitalismo industrial, parecía a punto de florecer. La nueva "sociedad internacional" venía gestándose a fuego lento en el mundo antiguo y comienza a configurarse desde la caída del Imperio Romano. La mercancía del capital configura un entramado de relaciones sociales que abarca virtualmente la totalidad de la población humana en el planeta (Levín, 1997: 17-44).

El hombre moderno entabla su relación social en esa nueva estructura. De hecho, no hay otra relación social general entre los individuos que la mercancía, ni otra forma de circulación general de la riqueza social que el mercado (Levín, 2010: 253-254). Tal es, en efecto, la novedad de la sociedad moderna. Y la mercancía, una relación social reificada, impersonal, ha cobrado la forma objetiva de universalidad. Sin embargo, la mercancía del capital no ha eliminado las relaciones sociales directas: las ha transformado, subsumiéndolas. Pero la experiencia cotidiana del hombre mercantil (a la que apela Smith) desmiente su propia verdad esencial, y su conciencia así obnubilada solo reconoce relaciones más próximas, (al parecer) inmediatas. De esta suerte, el homo mercator, el primer hombre histórico que entabló una relación humana objetivamente universal, ignora su propia realización suprema y vive de espaldas a su novísima dimensión.

En la TSM, Smith retrata una vida moral que no se desenvuelve en el reino natural ecuménico de la mercancía del capital, sino en un ámbito más restringido, donde la fragmentación mercantil de la comunidad no se ha consumado por completo, donde los individuos no son entidades recíprocamente indiferentes que solo entablan un vínculo social evanescente en el acto de compraventa; donde no se relacionan como "personas impersonales", de suerte que cada uno no considera a los demás como otros tantos instrumentos virtuales de los que podría valerse oportunamente (Marx); donde el hombre no es el lobo del hombre (Hobbes); y donde, en definitiva, todos los hombres y mujeres son aceptados y reconocidos. Esta esfera de relaciones humanas sobrevivió al derrumbe de las sociedades antiguas $\mathrm{y}$, en parte, al efecto erosivo y deletéreo de las relaciones mercantiles, dinerarias y capitalistas. 
La TSM remite entonces a un ámbito de relaciones sociales que no está afectado por la dicotomía ilustrada, resumida a comienzos del siglo XIX por Hegel, entre dos esferas de relaciones sociales generales: la sociedad civil y la sociedad política. Considerada abstractamente circunscripta a tal ámbito, la sociedad moderna no puede prescindir de ciertos valores morales. Pero la armonía (o la estabilidad) social general de una sociedad compleja y ecuménica no podrá reposar sobre las virtudes que cultivaban las filosofías antiguas y medioevales. Estas, explica Smith, se tornan superfluas o incluso contraproducentes (Fitzgibbons, 1995: 45-52).

El proyecto ilustrado de civilización moderna en el que se inscribe la investigación de Smith es incompatible con el poder despótico, incluso si es ejercido por sabios, héroes o santos, de modo que las virtudes en las que puede fundarse esta sociedad deben ser asequibles a los hombres y mujeres comunes y, más aún, deben ser connaturales a sus temperamentos e inclinaciones espontáneas (Levín, 2000). El siglo de la filosofía inquiere sobre la naturaleza y el entendimiento humano ${ }^{2}$ porque considera que la suerte de la sociedad moderna está a merced del hombre desencadenado, libre de las ataduras de la esclavitud y de todo vínculo de dependencia personal. Pero ¿es viable la armonía social si el hombre se libera de las cadenas milenarias? Smith sostiene que la criatura humana socialmente emancipada no es necesariamente una bestia narcisista y egoísta, insensible al interés del prójimo, pero tampoco un ser incondicionalmente consagrado al amor altruista.

En búsqueda de un principio universal de armonía para un mundo de hombres libres, Smith presenta el escenario de los "sentimientos morales" valiéndose para ello de la metáfora del teatro (Griswold, 1999: 65-70). El teatro del mundo se centra en la relación entre actor y espectador. Esta relación no es extrínseca; pero posee carácter polar, de modo que, a la vez que interactúa con espectadores externos, el actor se desdobla interiormente en actor y espectador.

El individuo moderno, en tanto su actividad es actuación, entabla una relación esencial a su condición humana con el espectador. Sus necesidades, sus deseos, sus metas y objetivos, en tanto son necesidades, deseos, etc., de carácter humano, son naturalmente mediados por la aprobación, ora de un espectador, ora de otro, hasta que gradualmente, por medio de una elaboración que coincide con el proceso madurativo y la elevación de la personalidad del individuo, este construye en su espíritu una representación más o menos acabada, del espectador social. En la capacidad individual de 
interpretar la opinión común para construir la figura del "espectador imparcial" se conjugan la imaginación y los sentimientos de sociabilidad. Pero, como desarrollaremos en el próximo apartado, el espectador imparcial, así como imprime autoridad sobre la conducta del individuo, e influye sobre sus motivos más profundos, también limita su capacidad de tomar en consideración valores universales y amenaza su equidad.

En el sistema de Smith los valores morales no provienen (como sí en la filosofía crítica kantiana) de una razón que, desplegándose con arreglo al concepto inmanente, dicta al individuo máximas de carácter necesario y universal; sino que estas son elaboradas por el individuo para satisfacer su necesidad emotiva de complacer al espectador. El individuo se desprende de la inmediatez de la aceptación, del reconocimiento o del aplauso, aprende a no ser presa de la lisonja o el agravio; pero, aunque mediada, la aprobación del espectador es aún una necesidad fundamental. El carácter cabalmente representativo del espectador figurado, su universalidad, y, en definitiva, su imparcialidad, admiten grados, y están sujetos a la inestabilidad e incluso a sufrir una reversión desastrosa: el sistema que debía ofrecer un fundamento a la civilización moderna se torna entonces virtualmente en su contrario, y se vuelve cómplice de una exacerbación de sentimientos que favorecen intereses colectivos, pero no universales (Griswold, 1999: 19-20; 77; Piqué, 2017: 130).

En la TSM, la universalidad del mundo moderno no brota del amor cristiano, porque es abstracto y porque supone una igualdad igualmente abstracta, ni de las virtudes estoicas, porque son particulares y niegan la igualdad, ni del egoísmo universal, porque los intereses privados son la negación de toda virtud; de modo que por el lado negativo la crítica es contundente y completa. Pero si Smith busca el fundamento natural de esa universalidad en los sentimientos morales connaturales al individuo determinado por lazos de simpatía y benevolencia, no es eso lo que encuentra. Será en la $R N$ donde se asomará a tal condición por medio de la exposición de los fundamentos de la sociedad comercial y de los fundamentos jurídicos para que esta devenga en una sociedad bien gobernada.

\section{La teoría de los sentimientos morales. Reconstrucción retrospectiva del argumento smithiano}

\section{La simpatía como fundamento de la armonía social}


En la TSM Smith se propone estudiar los principios que gobiernan la conducta de las personas y que hacen posible la vida social3. No en cualquier sociedad, sino en la novedosa sociedad comercial que se desplegaba a lo largo y a lo ancho del mundo existente, en la cual la persecución del interés individual ocupaba un lugar cada vez más destacado. ¿Qué principios de la naturaleza humana garantizan la paz y la prosperidad en una sociedad de estas características, en la cual la proliferación de las conductas egoístas supone una amenaza al orden social? ¿Qué mecanismo asegura la armonía social de una sociedad que deja atrás la moral cristiana, que pretende librarse del tutelaje y que trae consigo la promesa de una civilización universal? En la primera oración de la TSM Smith introduce el principio general sobre el que apoyará una primera respuesta a la pregunta acerca de la viabilidad de la sociedad moderna, la simpatía (sympathy):

por más egoísta que se pueda suponer al hombre, existen evidentemente en su naturaleza principios que le hacen interesarse por la suerte de otros y hacen que la felicidad de éstos le resulte necesaria, aunque no derive de ella nada más que el placer de contemplarla (Smith, 2013: 49).

Smith se esfuerza por mostrarle al lector que el hombre no es un ser eminentemente egoísta como lo retrataban autores como Mandeville o Hobbes 4 . Por el contrario, sostiene que todo ser humano posee una disposición natural a interesarse por la suerte de los demás, a alegrarse con sus alegrías y a entristecerse con sus penas. Es decir, a simpatizar, entendida la simpatía como la compañía en el sentimiento ante cualquier pasión. Mientras que la virtud de la benevolencia requiere una sensibilidad mayor a la que posee el común de las personas, "ni el mayor malhechor ni el más brutal violador de las leyes de la sociedad" se ve desprovisto de la disposición natural a simpatizar (Smith, 2013: 49; 75). En ocasiones, la simpatía se produce por la simple contemplación de una emoción, como ser el sonreír al observar un rostro risueño o encogerse al presenciar un golpe, pero en ese caso, aclara Smith, es sumamente imperfecta. El concepto de simpatía que Smith se esfuerza por erigir como el principio que guía la conducta humana y que explica la armonía social requiere de la mediación de la imaginación5.

Para identificarse y simpatizar, el individuo necesita conocer las circunstancias que originaron las pasiones del otro. Ello le permite imaginarse en su situación y comprobar o no si los sentimientos y las conductas del otro coinciden con los que él desarrollaría si estuviera en esa 
situación. Para ello, se basa en el conocimiento que tiene sobre experiencias pasadas, tanto vividas por él mismo como por personajes de obras literarias, familiares, amigos, conocidos. Pero no solo es el ser humano capaz de simpatizar, sino que todo ser humano busca y desea la simpatía como actor y como espectador: no se trata del interés propio, no se espera de la compañía más que la satisfacción que ocasiona.

La simpatía se convierte así en una guía para juzgar la conducta propia y ajena. Movidos por el deseo de obtener simpatía y de simpatizar, actores y espectadores moderan y corrigen sus pasiones para que puedan ser acompañadas y juzgadas correctas ${ }^{6}$. El hombre nace y se cultiva en sociedad observando los juicios que realizan los individuos sobre la conducta de otros $\mathrm{y}$, de esa manera, aprende a juzgar tanto a los otros como su propia conducta7 ${ }^{7}$ Así, mide y ajusta su propia conducta colocándose en el lugar de un "espectador imparcial", que sintetiza lo que es socialmente correcto o incorrecto ${ }^{8}$. "Nuestra continua observación de la conducta ajena nos conduce insensiblemente a formarnos unas reglas generales sobre lo que es justo y apropiado hacer o dejar de hacer" (Smith, 2013: 282-283). Por medio de este proceso, los sentimientos devienen morales, modelados y moderados en una cultura social específica (Rodríguez Braun, 2013: 13). Se logra así "corregir las tergiversaciones del amor propio con relación a lo que es justo y apropiado hacer" (Smith, 2013: 285).

Hasta aquí, el principio de simpatía oficia de fundamento de la armonía y paz social. Sin embargo, el propio autor reconoce el alcance limitado de la simpatía en una "sociedad de extraños"9. Como hemos señalado más arriba, Smith busca explicar los principios que guían la conducta de los hombres en la nueva sociedad comercial que tiende a la universalidad, en la cual se funden culturas particulares distintas y en la cual se van perdiendo los lazos de proximidad que permiten una identificación común y simpatía natural ${ }^{10}$. El principio de simpatía que desarrolla Smith tiene vigencia en el contexto de una "sociedad pequeña", relativamente estática, en la que sus miembros se conocen y tienen trato constante. Pero estas son, por supuesto, características opuestas a aquellas de la sociedad comercial, dinámica, cambiante, universal. A medida que la sociedad se expande y se convierte en una sociedad de extraños, el principio de simpatía e identificación común deja de tener vigencia como principio general. Su alcance se circunscribe a ámbitos sociales reducidos, particulares, en los cuales el individuo elabora sus nociones sobre lo 
aprobable y no aprobable, observando el comportamiento de otros miembros de ese grupo social específico.

La exposición del concepto de simpatía, fuente de cohesión en culturas locales y potencialmente también de graves tensiones en la sociedad comercial, puede comprenderse como una de las razones que lleva a Smith a incursionar en el campo de la jurisprudencia, en el que se inscribe su economía política (Piqué, 2017: 165). Una de las claves del sostenimiento de una sociedad en la cual los individuos conviven pacíficamente sin amor o afecto mutuo, como la de sociedad de comerciantes, es la prevalencia de la justicia (Piqué, 2017: 133)11. Si esto no ocurriera, "la destrucción de la sociedad sería completa"12. Aparece así una virtud que puede ser exigida por la fuerza.

En su búsqueda de los fundamentos de una sociedad viable que disfrute de los beneficios del comercio moderno Smith se sumerge en el estudio de la jurisprudencia, donde espera dar con "los principios generales de la legislación y el gobierno", las "reglas naturales de la justicia", que "debían constituir los fundamentos de las leyes de todas las naciones" (Smith, 2013: 577-578), en un mundo internacional donde hombres extraños entre sí convivan pacíficamente a partir del intercambio de buenos oficios $^{13}$. Allí Smith apuntará a bosquejar las leyes e instituciones que permitan una civilización donde prime la identificación común y por tanto se evite el daño entre los miembros de la sociedad.

Es precisamente ese proyecto el que conduce a Smith a incursionar en los terrenos de la economía política. En su investigación sobre la naturaleza y causas de la riqueza de las naciones busca el fundamento científico que serviría a legisladores y gobernantes en el arte del buen gobierno ${ }^{14}$. La economía política tiene la misión de guiar a los gobernantes y legisladores en la consecución de un sistema de jurisprudencia que resguarde a la sociedad de los posibles males que podían devenir del desarrollo capitalista. En la sexta revisión de la TSM indica que en la $R N$ cumplió en parte con sus objetivos, al menos en lo concerniente a la administración, las finanzas públicas y la defensa, pero que sigue pendiente una teoría de la jurisprudencia, "un proyecto largamente acariciado" (Smith, 2013: 44) que no podrá completar.

\section{La riqueza de las naciones. Reconstrucción retrospectiva del argumento smithiano}




\section{Concepto de valor: nuevo mecanismo de articulación social}

En la $R N$ el hombre no procura su sustento invocando los sentimientos humanitarios del resto de los miembros de la sociedad: debe apelar al interés del otro para proveerse de las cosas necesarias y convenientes para la vida.

En una sociedad civilizada necesita a cada instante la cooperación y asistencia de la multitud, en tanto su vida entera le basta para conquistar la amistad de contadas personas [...] La conseguirá con mayor seguridad interesando en su favor el egoísmo de los otros y haciéndoles ver que es ventajoso para ellos hacer lo que les pide (Smith, 2004: 16).

No es la benevolencia del carnicero, del cervecero o del panadero la que nos procura el alimento, sino la consideración de su propio interés. No invocamos sus sentimientos humanitarios sino su egoísmo; ni les hablamos de nuestras necesidades, sino de sus ventajas (Smith, 2004: 17).

La expansión del comercio convierte al mundo en un gran mercado y "el hombre vive así, gracias al cambio, convirtiéndose, en cierto modo, en mercader, y la sociedad misma prospera hasta ser lo que realmente es, una sociedad comercial" (Smith, 2004: 24). El hombre se libera de las ataduras de los vínculos de dependencia personal y se relaciona con el resto del mundo a través del intercambio mercantil. La extensión del mercado permite una división del trabajo y un aumento de la productividad inéditos y prometedores. Ese desarrollo de la mercancía trae consigo la opulencia de las naciones y las promesas de libertad y progreso, pero Smith no olvida en la $R N$ el problema que quedó planteado en la TSM: solamente en una sociedad "bien gobernada", dice en la $R N$, el desarrollo del comercio se traduce en progreso universal15. La necesidad de una "evaluación consensuada" que había sido planteada en la TSM se refuerza en la $R N$, que tiene como protagonista a la relación mercantil y, por consiguiente, a la búsqueda del interés privado.

Las tensiones entre el capitalismo y la promesa de una sociedad civilizada aparecen a lo largo de la obra. En lo que respecta a la división del trabajo, además de sus famosos elogios en las primeras páginas del Libro I, escribe en el Libro $\mathrm{V}$ que la especialización puede también embrutecer la mente y el espíritu: 
Con los progresos en la división del trabajo la ocupación de la mayor parte de las personas que viven de su trabajo, o sea, la gran masa del pueblo, se reduce a muy pocas y sencillas operaciones [...] Adquiere, pues, la destreza en su oficio peculiar, a expensas de sus virtudes intelectuales, sociales y marciales. Aún en las sociedades civilizadas y progresivas, este es el nivel a que necesariamente decae el trabajador pobre, o sea la gran masa del pueblo, a no ser que el gobierno se tome la molestia de evitarlo (Smith, 2004: 687).

En la nueva sociedad comercial, no lo dice Smith, pero lo sabemos nosotros, los dos momentos de la producción, el momento de transformación técnico material mediado por el trabajo humano y el momento de intercambio social, se encuentran escindidos (Levín, 2003). En el mercado se completa el proceso por el cual el producto individual se convierte en producto social y el trabajo individual en trabajo social. La relación mercantil, un tipo históricamente específico de intercambio social, se distingue de toda otra forma de intercambio por su carácter voluntario, impersonal, evanescente, fugaz y universal. A diferencia de las relaciones directas y jerárquicas características de otras sociedades humanas, la relación mercantil se caracteriza por la ausencia de todo poder de planificación: requiere la conjunción de dos voluntades libres y socialmente iguales. ¿En qué proporción se intercambian las mercancías? ¿Qué fuerzas determinan qué y cuánto se produce para llevar al mercado? ¿Qué leyes garantizan el equilibrio del sistema económico? En otras palabras, ćcómo se asigna el trabajo en una sociedad de individuos recíprocamente extraños, en la cual no existe una planificación económica de conjunto? ¿Qué mecanismo regula la reproducción de la vida social? Smith intenta desarrollar una explicación del proceso de reproducción de mercancías (incluido el intercambio mercantil) fundada en la noción de valor, que el autor recoge del pensamiento antiguo y medieval y de la experiencia práctica común de su época ${ }^{16}$. En el principio general del valor apoya una nueva respuesta a la pregunta acerca de la viabilidad de la sociedad de extraños que no había logrado responder en la $T S M$, pero también en esta empresa fracasa a poco de andar.

En el estado rudo y primitivo de la sociedad, que precede a la acumulación del capital y a la apropiación de la tierra, la única circunstancia que puede servir de norma para el cambio recíproco de diferentes objetos parece ser la proporción entre las distintas clases de trabajo que se necesitan para adquirirlos. Si en una nación de cazadores, por ejemplo, cuesta usualmente el doble 
trabajo matar un castor que un ciervo, el castor, naturalmente, se cambiará por o valdrá dos ciervos. Es natural que una cosa que generalmente es producto del trabajo de dos días o de dos horas valga el doble que la que es consecuencia de un día o de una hora (Smith, 2004: 47).

En una sociedad pequeña, simple y estática, con un mercado incipiente, donde los procesos técnicos son conocidos por todos sus miembros, los productos son pocos y sus técnicas no varían significativamente en el tiempo, los individuos tienen una percepción práctica basada en su experiencia de la cantidad social promedio de trabajo que se necesita para reproducir cada mercancía. Es decir, tienen una noción práctica del valor de las mercancías. En ese contexto, las mercancías no se cambian necesariamente de acuerdo con sus valores, ya que la escasez relativa de una u otra mercancía en el mercado altera la relación de cambio. Sin embargo, como los productores conocen las "penas y fatigas" que suponen los distintos trabajos, saben qué mercancías se están intercambiando por encima de sus valores y cuáles por debajo. Si el trabajo es para ellos un instrumento, es decir un medio para alcanzar un fin, entonces se comportarán de manera tal de ahorrar trabajo o energía. Algunos individuos optarán por dejar de producir aquellas mercancías cuya relación de cambio es menor que su relación de valor y destinarán su tiempo de trabajo a producir las que se venden por encima de su valor. $\mathrm{Al}$ aumentar la oferta de las primeras y disminuir la de las segundas, las relaciones de cambio en el mercado tenderán a igualarse a las de valor.

Es imperioso que los individuos conozcan los tiempos de trabajo necesarios para la reproducción de las mercancías para que opere la ley del valor tal como está formulada en la $R N$. Solo en ese contexto es posible explicar a través de qué mecanismo las relaciones de cambio en el mercado gravitan en torno a la relación entre sus respectivos valores. Smith es consciente de que ese supuesto tiene vigencia solamente en una sociedad pequeña, simple y estática, pero a él le interesa explicar el desenvolvimiento de la sociedad comercial que tiende a la universalidad. Mientras en las primeras páginas de su obra había explicado que la mercancía no puede desarrollarse si no se despliega en un ámbito que tiende a abarcar el mundo entero, su ley del valor solamente puede explicar de qué manera el valor rige el movimiento de los precios en un mercado hipotético, simple, diminuto, estático; a saber, en "la sociedad ruda y primitiva". Al pasar a la sociedad comercial, universal y dinámica, no consigue explicar de qué manera opera 
o tiene efecto práctico la ley del valor, y, en consecuencia, la abandona ${ }^{17}$. El concepto de valor desaparecerá en el resto de su obra.

\section{Conclusiones y perspectivas}

El problema al que se había enfrentado Smith en la TSM reaparece, mutatis mutandis, en la $R N$. En ambas obras intenta brindar una respuesta al problema de la viabilidad y sostenibilidad de la sociedad moderna apoyándose sobre un principio de la vida práctica: el principio de simpatía y el principio de valor. Smith se esfuerza por partir de experiencias prácticas ordinarias, procurando no cortar el lazo con esa experiencia a medida que va desarrollando su argumento, pero en ambas obras las nociones de simpatía y de valor no alcanzan un grado de maduración suficiente como para convertirse en conceptos articuladores de una teoría general sobre el comportamiento de la sociedad moderna. Ambos principios, no cabalmente desarrollados, tienen vigencia en una sociedad pequeña y simple, pero resultan insuficientes para explicar el desenvolvimiento de una sociedad universal.

Ambos "fracasos" ponen de relieve el problema, abordado, pero no resuelto cabalmente para el campo de las ciencias sociales por la filosofía del siglo XVIII: el de la producción de conceptos teóricos universales en una sociedad compleja, en constante transformación y que aspira a la universalidad. El esfuerzo de Smith por partir de nociones de la experiencia práctica y convertirlas en conceptos teóricos se inscribe en la aspiración de la Ilustración de alcanzar una síntesis de conocimientos generales que no reposara en principios últimos inmutables inaccesibles a la experiencia humana.

Retrospectivamente encontramos que ambos tropiezos de Smith, primero en la TSM y luego en la $R N$, constituyen invaluables aportes, importantes problemas teóricos irresueltos, largamente desatendidos, que hoy se vuelve urgente retomar y completar. Si de suyo es relevante para la economía política el problema de cómo opera la ley del valor en la sociedad capitalista ${ }^{18}$, más aún lo es como parte integrante del proyecto general del autor: desarrollar por medio de una teoría de la jurisprudencia el fundamento de las instituciones políticas que permitieran concretar un proyecto civilizatorio.

Nos hacemos hoy la misma pregunta que abordó y no resolvió la Ilustración de hace dos siglos. ¿Son compatibles con el capitalismo las 
promesas de la Revolución francesa: libertad, igualdad, fraternidad, democracia, progreso y justicia universales? Si se realizara la Democracia, las restantes vendrían de suyo. Entonces, des compatible el capitalismo con la democracia? Y nuevamente en términos inspirados más directamente en Smith, ¿cómo convertir la simpatía particular en solidaridad universal no abstracta ni mítica? ¿Puede una sociedad de carácter universal planificar democráticamente su reproducción, su vida social, en definitiva, su historia próxima? ¿Cuál es la relación de la economía política con otros campos de las ciencias sociales, y especialmente con la filosofía?

Hoy, el Estado moderno reducido a Estado nacional es la negación de su propósito universal, la democracia no lo es, la civilización universal es solo abstractamente universal, la filosofía no ha logrado desprenderse de la metafísica ${ }^{19}$. La revolución burguesa tuvo dos caras: de un lado las luces, los derechos del hombre moderno, el progreso universal. Del otro la oscuridad, el saqueo del resto del mundo, la servidumbre, la explotación. Pero aun con todos sus espantos, instaló un progreso irreversible: sus promesas pasaron a formar parte del concepto irrenunciable de condición humana.

Si bien no fue el propósito de su autor, la $R N$ marcó el nacimiento de la economía política como ciencia autónoma, encargada de develar las leyes del sistema económico. A partir de entonces la economía política se iría configurando como la ciencia de la sociedad civil, divorciada de la filosofía y del resto de las llamadas ciencias sociales. Aquel proceso de fragmentación permitió invaluables avances en la comprensión de la sociedad capitalista. Entre ellos, destacamos especialmente el desarrollo del concepto de la génesis del dinero de Carlos Marx, quien, partiendo de la ficción sociedad civil-Estado moderno, desarrolló la teoría de la mercancía de la sociedad civil hasta el punto de subvertirla y mostrar su agotamiento ${ }^{20}$. Hoy, cuando la ficción de la sociedad civil resulta anacrónica y la fragmentación de la economía política en pos de la especialización alcanza límites insostenibles, encontramos inspiración en la obra de Smith para repensar -con la ventaja retrospectiva teórica e histórica de los siglos XIX, XX y XXI- los lazos de la economía política con otros campos de las ciencias sociales, y más relevante aún, su posible papel, en perspectiva programática, en la producción de una estrategia histórica de transformación social. Esta tarea avizora los prolegómenos de una nueva Ilustración. 


\section{Referencias Bibliográficas}

Fitzgibbons, A. (1995). Adam Smith's system of liberty, wealth, and virtue: The moral and political foundations of "The wealth of nations". Oxford: Clarendon Press.

Griswold, C. L. (1999). Adam Smith and the virtues of enlightenment. Cambridge: Cambridge University Press.

Hobbes, T. (2004) [1651]. Leviatán o La materia, forma y poder de un estado eclesiástico y civil. Madrid: Alianza.

Hume, D. (2011) [1739]. A treatise of human nature (First publ. in paperback). Oxford: Clarendon Press.

Kant, I. (1985). Filosofía de la historia (1. ed., 4. reimpr). Ciudad de México: Fondo de Cultura Económica.

Levín, P. (1997). El capital tecnológico. Buenos Aires: Catálogos.

Levín, P. (2000). "Political economy at the close of its subject matter". The Journal of Management and Economics, 4(4), 1-28.

Levín, P. (2003). "Ensayo sobre la Cataláctica”. Revista Nueva Economía, 13(20), 1-21.

Levín, P. (2010). "Esquema de la ciencia económica". Revista de Economía Política de Buenos Aires, 4(7 y 8), 247-289.

Levín, P., Piqué, M. del P. \& Cazenave, A. (2018). "Ensayo sobre el posible aporte de la economía política a la filosofía de la aspiración". RInERS. Revista de Investigación en Economía y Responsabilidad Social, 1(2), 19-34.

Mandeville, B. de (1982) [1714]. La fábula de las abejas o Los vicios privados hacen la prosperidad pública (1. ed. en español). Ciudad de México: Fondo de Cultura Económica.

Piqué, P. (2017). La obra de Adam Smith en el estudio y en la enseñanza de la historia del pensamiento económico [Tesis doctoral]. Universidad de Buenos Aires.

Rodríguez Braun, C. (2013). Estudio preliminar. En Smith, A. La teoría de los sentimientos morales (pp. 7-35). Madrid: Alianza.

Screpanti, E. \& Zamagni, S. (2005). An outline of the history of economic thought (2nd ed. rev. and expanded). Oxford: Oxford University Press.

Smith, A. (2004) [1776]. Investigación sobre la naturaleza y causas de la riqueza de las naciones. Ciudad de México: Fondo de Cultura Económica.

Smith, A. (2013) [1759]. La teoría de los sentimientos morales. Madrid: Alianza.

\footnotetext{
${ }^{1}$ El Dr. Pablo Enrique Levín falleció habiendo sido ya presentado este artículo a los editores.

${ }^{2} \mathrm{Si}$ a la sazón la filosofía moral iba a la zaga de la filosofía de la naturaleza, el esperado progreso en el conocimiento de las capacidades cognitivas del hombre, y más ampliamente en la "ciencia de la naturaleza humana", denominada así por David Hume, había de inaugurar una nueva época para todas las ciencias. En palabras del mismo Hume, "es imposible decir cuántos avances y mejoras podríamos realizar en esas ciencias si lográramos familiarizarnos por
} 
completo con el alcance y la fuerza del entendimiento humano, y si pudiéramos explicar la naturaleza de las ideas que empleamos y de las operaciones que llevamos a cabo en nuestros razonamientos" (Hume, 2011: 4, trad. propia).

3 Como señala Griswold (1999: 44), Smith no incluye en la TSM una introducción en la cual se presente el propósito de la obra. Recién en la Parte VII el autor señala dos problemas que deben considerarse al abordar los principios de la moral: en qué consiste la virtud y mediante qué poder o facultad de la mente resulta recomendable dicho carácter (Smith, 2013: 459-460). Asimismo, en el Libro $\mathrm{V}$ de la $R N$ Smith se refiere a la filosofía moral como la ciencia que investiga los principios generales que rigen la conducta de los individuos y permiten la vida social, del mismo modo que la filosofía natural hace lo propio con los fenómenos de la naturaleza (Smith, 2004: 678). En la cuarta edición de la TSM Smith añadió un subtítulo que luego quitó de las ediciones siguientes y que también explicaba el problema que abordaba (Rodríguez Braun, 2013: 13): La teoría de los sentimientos morales, o un ensayo de análisis de los principios por los cuales los hombres juzgan naturalmente la conducta y personalidad, primero de su prójimo y después de sí mismos.

${ }_{4}$ Smith alude explícitamente a estos autores en la Parte VII de la TSM, en la cual realiza una reconstrucción de los progresos realizados en el campo de la filosofía moral hasta la publicación de su obra. Antes que Smith, otros autores de la Ilustración escocesa como Hutcheson y Hume también habían buscado rebatir aquella postura y mostrar que no era el egoísmo el principio que guía la conducta humana.

5 "La imaginación nos permite situarnos en su posición, concebir que padecemos los mismos tormentos, entrar por así decirlo en su cuerpo y llegar a ser en alguna medida una misma persona con él y formarnos así alguna idea de sus sensaciones e incluso sentir algo parecido, aunque con una intensidad menor" (Smith, 2013: 50).

6 "La naturaleza, cuando formó al ser humano para la sociedad, lo dotó con un deseo original de complacer a sus semejantes y una aversión original a ofenderlos. Le enseñó a sentir placer ante su consideración favorable y dolor ante su consideración desfavorable. Hizo que su aprobación le fuera sumamente halagadora y grata por sí misma, y su desaprobación muy humillante y ofensiva" (Smith, 2013: 230).

7 "Aprobamos o desaprobamos nuestra propia conducta si sentimos que, al ponernos en el lugar de otra persona y contemplarla, por así decirlo, con sus ojos y desde su perspectiva, podemos o no podemos asumir totalmente y simpatizar con los sentimientos y móviles que la influyeron" (Smith, 2013: 221).

8 "Solo por él conocemos nuestra verdadera pequeñez y la de lo que nos rodea, y las confusiones naturales del amor propio solo pueden ser corregidas por la mirada de este espectador imparcial" (Smith, 2013: 260). "El hábito y la experiencia nos han adiestrado para hacer esto de forma tan sencilla y pronta que apenas nos damos cuenta de que lo hacemos" (Smith, 2013: 258-259).

9 "Aunque los hombres tienen simpatía natural, sienten muy poco hacia alguien con quien no mantienen una conexión especial en comparación con lo que sienten hacia sí mismos; la miseria de alguien que sólo es un semejante resulta de importancia insignificante para ellos en comparación a una minúscula comodidad propia" (Smith, 2013: 183-184).

10 Smith había advertido que las personas que no logren simpatizar mutuamente pueden volverse recíprocamente intolerables (Smith, 2013: 69).

11 "Aunque entre los distintos miembros de la sociedad no haya amor y afecto recíprocos, la sociedad, aunque menos feliz y grata, no necesariamente será disuelta. La sociedad de personas distintas puede subsistir, como la de comerciantes distintos, en razón de su utilidad, sin ningún amor o afecto mutuo; y aunque en ella ninguna persona debe favor alguno o está en deuda de gratitud con nadie, la sociedad podrá sostenerse a través de un intercambio mercenario de buenos oficios de acuerdo a una evaluación consensuada" (Smith, 2013: 182).

12 "La sociedad puede mantenerse sin beneficencia, aunque no en la situación más confortable; pero si prevalece la injusticia, su destrucción será completa. [...] [La beneficencia] es el adorno que embellece el edificio, no la base que lo sostiene [...] La justicia, en cambio, es el pilar fundamental en el que se apoya todo el edificio. Si desaparece entonces el inmenso tejido de la sociedad humana [...] en un momento será pulverizada en átomos" (Smith, 2013: 183).

${ }_{13}$ En el último párrafo de la TSM anuncia: "en otro estudio procuraré explicar los principios generales del derecho y el estado, y los grandes cambios que han experimentado a lo largo de 
los diversos períodos y etapas de la sociedad, no sólo en lo relativo a la justicia sino en lo que atañe a la administración, las finanzas públicas, la defensa y todo lo que cae bajo el ámbito legislativo. Por consiguiente, no entraré ahora en ningún detalle ulterior acerca de la historia de la jurisprudencia" (Smith, 2013: 578).

14 "La Economía Política, considerada como uno de los ramos de la ciencia del legislador o estadista, se propone dos objetos distintos: el primero, suministrar al pueblo un abundante ingreso o subsistencia o, hablando con más propiedad, habilitar a sus individuos y ponerles en condiciones de lograr por sí mismos ambas cosas; el segundo, proveer al Estado o República de rentas suficientes para los servicios públicos. Procura realizar, pues, ambos fines, o sea enriquecer al soberano y al pueblo" (Smith, 2004: 377).

15 "La gran multiplicación de producciones en todas las artes, originadas en la división del trabajo, da lugar, en una sociedad bien gobernada, a esa opulencia universal que se derrama hasta las clases inferiores del pueblo" (Smith, 2004: 14).

${ }^{16}$ El gran progreso de los primeros pensadores modernos que tratan los fenómenos económicos había sido precisamente despojar la pregunta sobre el movimiento de los precios de la justicia conmutativa teológica (Screpanti \& Zamagni, 2005: 31-32). El costo de ese progreso fue el abandono del concepto de valor.

17 En el capítulo VI del Libro I de la $R N$ Smith adopta los costos de producción como fundamento de los precios.

${ }^{18}$ Desarrollamos este problema en Levín (1997) y (2010).

19 Estas afirmaciones constituyen problemas de investigación que exceden a este trabajo, en los que estamos incursionando y que esperamos retomar en trabajos futuros.

${ }^{20}$ Ver Levín (1997) y (2010). 